\title{
EVALUASI DAN PERENCANAAN PENGEMBANGAN JARINGAN DISTRIBUSI PDAM PUSAT KABUPATEN SAMBAS
}

\author{
Imam Argono(1), Winardi Yusuf ${ }^{(1)}$, Eko Yulianto(2) \\ 1Program Studi Teknik Lingkungan Jurusan Teknik Sipil Fakultas Teknik Universitas Tanjungpura, Pontianak \\ ${ }^{2}$ Program Studi Teknik Sipil Jurusan Teknik Sipil Fakultas Teknik Universitas Tanjungpura, Pontianak \\ Email: imamargn@gmail.com
}

\begin{abstract}
ABSTRAK
Perusahaan Daerah Air Minum (PDAM) Tirta Muare Ulakan Kabupaten Sambas sebagai perusahaan yang bergerak dalam bidang pelayanan air minum/air bersih, dituntut untuk meningkatkan pelayanannya kepada masyarakat/pelanggan di Kabupaten Sambas. Tujuan dari penelitian ini adalah menganalisa kondisi eksisting sistem distribusi PDAM Pusat Kabupaten Sambas, mengevaluasi dan merencanakan pengembangan jaringan distribusi air bersih PDAM Pusat Kabupaten Sambas, dapat memenuhi 90\% dari jumlah kebutuhan air penduduk yang ada. Metode yang digunakan adalah dengan menganalisa kondisi eksisting jaringan pipa distribusi PDAM Pusat Kabupaten Sambas dan merencanakan pengembangan jaringan distribusi dengan menggunakan software Epanet 2.0. Berdasarkan hasil analisa terhadap kondisi eksisting didapat permasalahan yang harus di evaluasi yaitu peningkatan terhadap pelayanan, penurunan tingkat kehilangan air, peningkatan tekanan dan kontinuitas aliran.. Dari hasil simulasi didapat nilai tekanan terkecil pada jam 05.00 dan tekanan terbesar pada jam 00.00 karena pengaruh fluktuasi kebutuhan yang terjadi pada setiap jam. Tekanan mengalami penurunan disebabkan oleh meningkatnya pemakaian air oleh pelanggan dan tekanan mengalami peningkatan disebabkan oleh pemakaian air yang kecil oleh pelanggan. Untuk memenuhi seluruh kebutuhan yang ada harus dilakukan modifikasi terhadap jaringan pipa dan penggantian pompa serta menambah kapasitas produksi.
\end{abstract}

Kata Kunci : PDAM Kabupaten Sambas, Jaringan Pipa, Air Bersih

\section{ABSTRACT}

Perusahaan Daerah Air Minum (PDAM) Tirta Muare Ulakan Sambas Regency as a company that engaged in the field of water service/clean water, required to improve services for customer/society at Sambas Regency. The purpose from this research are analyzing existing condition of distribution system at PDAM Central of Sambas regency, evaluation and planned development of distribution networks clean water PDAM Central of Sambas Regency can satisfy 90\% from the amount of water needs of the existing population. Method that used are analyzing existing condition of distribution pipelines PDAM Central of Sambas Regency and planned development of distribution pipelines with using software EPANET 2.0. Based on the analysis of existing condition obtained problems that must be evaluated increase of service, reduction of water less, increased pressure and flow continuity. From simulation result obtained the smallest pressure value at 05.00 o'clock and the biggest pressure value at 00.00 o'clock because the effect of fluctuations in demand occurs at every hour. Reduction of pressure caused increase water consumption by customer and increasing pressure caused small water consumption by customer. To satisfy all the needs that exist must be do modification of pipeline and replacement pump also adding capacity production.

Keyword : PDAM Sambas Regency, Pipeline, Clean Water

\section{PENDAHULUAN}

Dalam Kehidupan ekonomi modern air adalah merupakan salah satu unsur pokok yang harus dipenuhi dan harus dapat tercukupi. Sebagai salah satu unsur utama dalam siklus kehidupan di muka bumi air juga harus dapat kita usahakan dan kelola dengan baik sehingga ketersediaan dan keberadaannya dapat lestari dan termanfaatkan dengan bijaksana. Sebaran air yang ada di muka bumi ini tidak merata sehingga ketersediaan air di suatu tempat sangat bervariasi. Dari waktu ke waktu kebutuhan air bersih bagi kehidupan manusia semakin meningkat sejalan dengan bertambahnya jumlah penduduk, sedangkan ketersediaan yang ada semakin terbatas, bahkan di beberapa daerah telah menjadi kritis. Oleh karena itu upaya peningkatan produksi air bersih perlu dilakukan dengan 
bijaksana. Hal inilah yang mendorong pemerintah untuk meningkatkan pemanfaatan dan pengelolaan terhadap sumber-sumber air yang ada. Dalam mengatasi permasalahan air tersebut maka diperlukan sistem penyediaan air yang mampu menyediakan air yang memenuhi standar kesehatan dimana air tersebut diambil dari sumber-sumber yang ada antara lain : air hujan, air permukaan (sungai, waduk dan danau), mata air, sumur dangkal dan lain-lain. Akan tetapi bearnya air berbeda-beda tergantung dari musim dan lokasi sumber airnya. Untuk menjamin ketersediaan air dan pengelolaan air serta distribusi air tersebut berupa Perusahaan Daerah Air Minum (PDAM). Perusahaan Daerah Air Minum (PDAM) Tirta Muare Ulakan Kabupaten Sambas sebagai perusahaan yang bergerak dalam bidang pelayanan air minum/air bersih, dituntut untuk meningkatkan pelayanannya kepada pelanggan/masyarakat di Kabupaten Sambas. PDAM Kabupaten Sambas berusaha memanfaatkan seoptimal mungkin sumber-sumber air yang ada untuk memberikan pelayanan air bersih secara lebih teratur dalam kuantitas air yang cukup dan kualitas air yang sesuai standar yang telah ditetapkan oleh Pemerintah Indonesia.

Tujuan dilakukannya penelitian ini adalah untuk menganalisa kondisi eksisting pada jaringan pipa distribusi PDAM Pusat Kabupaten Sambas, mengevaluasi dan merencanakan pengembangan jaringan distribusi PDAM Pusat Kabuoaten Sambas dalam usaha peningkatan prosentase pelayanan, dan diharapkan perencanaan ini dapat mencakup dan memenuhi $90 \%$ kebutuhan air masyarakat dalam wilayah pelayanan. Manfaat yang diharapkan dari perencanaan ini adalah diperoleh gambaran kondisi distribusi air bersih sebagai pertimbangan PDAM Kabupaten Sambas dalam melakukan evaluasi dan perencanaan pengembangan jaringan distribusi dalam upaya peningkatan pelayanan.

\section{METODE PENELITIAN}

Perencanaan ini dilakukan di Kecamatan Sambas Kabupaten Sambas yang meliputi daerah pelayanan PDAM Pusat Kabupaten Sambas. Wilayah Pelayanan ini meliputi 18 desa di Kecamatan Sambas yaitu Desa Sungai Rambah, Desa Gapura, Desa Kartiasa, Desa Saing Rambi, Desa Lumbang, Desa Durian, Desa Pasar Melayu, Desa Pandawan, Desa Tanjung Bugis, Desa Lubuk Dagang, Desa Dalam Kaum, Desa Tanjung Mekar, Desa Tumuk Manggis, Desa Jagur, Desa Lorong, Desa Sebayan, Desa Sumber Harapan, dan Desa Semangau yang merupakan kawasan permukiman, pusat perdagangan, komersil, perkantoran, sekolah, industri, pariwisata dan fasilitas umum lainnya. Perencanaan ini dilaksanakan selama kurang lebih 5 bulan yang dimulai dari bulan Agustus 2014 hingga Januari 2015.

Kegiatan pelaksanaan penelitian tentang evaluasi dan perencanaan pengembangan jaringan distribusi PDAM Pusat Kota Sambas adalah sebagai berikut:

1. Melakukan pengecekan terhadap data-data yang telah diperoleh, yaitu data topografi, data kependudukan, data jaringan, data debit dan data karakteristik pemakaian air.

2. Melakukan simulasi jaringan eksisting sistem distribusi dengan menggunakan program EPANET 2.0 berdasarkan data yang diperoleh, yaitu kondisi konfigurasi jaringan dan topografi, dengan input data yang meliputi data fisik jaringan, interkoneksi jaringan, serta aksesoris jaringan pipa.

3. Melakukan analisis terhadap kondisi jaringan eksisting yang telah disimulasikan. Analisis jaringan tersebut meliputi analisis terhadap diameter pipa, head tiap node, debit yang mengalir pada tiap pipa, dan head pada pompa.

4. Melakukan evalusi dan perencanaan pengembangan jaringan berdasarkan hasil analisis kondisi jaringan eksisting.

Pada penelitian ini, analisa dilakukan dengan mengolah data-data yang telah diperoleh, kemudian disesuaikan dengan pustaka-pustaka serta hasil terdahulu yang terkait. Analisa terhadap data primer maupun sekunder, yang telah diperoleh meliputi:

A. Analisa Kependudukan

Data kependudukan yang digunakan adalah data penduduk Kota Sambas, analisa ini dilakukan untuk mengetahui jumlah, tingkat kepadatan, dan pertumbuhan penduduk Kota Sambas. Perkiraan jumlah penduduk di masa akan datang mengacu pada besarnya angka pertumbuhan 
penduduk yang didapat dari BPS Kabutapen Sambas. Secara teoritis metode proyeksi ada beberapa macam, diantaranya metode Aritmatik, Geometri serta Least Square.

B. Analisa Kebutuhan Air

Besarnya kebutuhan air penduduk kota sedang mengacu kepada Dirjen Cipta Karya, tahun 2000 yaitu sebesar $100 \mathrm{l}$ /orang/hari dengan faktor hari maksimum sebesar 1,1 dan faktor jam puncak sebesar 1,5 dan jumlah jiwa per sambungan rumah sebanyak 5 orang sehingan dapat diketahui kebutuhan air penduduk per tahun. Selanjutnya tingkat pelayanan air dianalisis dengan mengambil tingkat pelayanan $90 \%$ terhadap jumlah penduduk Kota Sambas.

C. Analisa Kondisi Jaringan Eksisting

Analisa kondisi jaringan eksisting diperlukan untuk mengetahui kondisi jaringan distribusi PDAM Pusat Kota Sambas yang akan dijadikan studi kasus dalam tugas akhir ini. Adapun data yang diperlukan dalam analisa ini sebelum simulasi jaringan adalah peta eksisting jaringan pipa, data jumlah pelanggan PDAM Pusat Kota Sambas, data pipa dan data pompa.

D. Perencanaan Jaringan Dengan EPANET 2.0

Proses perencanaan sistem distribusi air bersih terdiri dari menentukan kebutuhan air di setiap wilayah pelayanan, menentukan jalur pipa dan jarak pipa distribusi air bersih, serta perhitungan hidraulik meliputi kehilangan energi, sisa tekan, head pompa, kapasitas dan jenis pompa.

\section{HASIL DAN PEMBAHASAN}

A. Proyeksi Kebutuhan Air

Berikut hasil perhitungan proyeksi kebutuhan air masyarakat Kecamatan Sambas (Hasil Analisa, 2014):

Tabel 1. Proyeksi Kebutuhan Air

\begin{tabular}{|l|c|r|r|r|r|}
\hline \multirow{2}{*}{ Deskripsi } & \multirow{2}{*}{ Satuan } & \multicolumn{4}{|c|}{ Tahun Perencanaan } \\
\cline { 3 - 6 } & & 2015 & 2020 & 2025 & 2030 \\
\hline Jumlah Penduduk : & Jiwa & 43.883 & 51.743 & 59.603 & 67.463 \\
\hline & & & & & \\
\hline $\begin{array}{l}\text { Penduduk yang dilayani } \\
\text { melalui : }\end{array}$ & & & & & \\
\hline - Sambungan Rumah : & $(\%)$ & 30 & 50 & 70 & 90 \\
\hline - Jumlah Jiwa yg terlayani & Jiwa & 13.165 & 25.872 & 41.722 & 60.717 \\
\hline - Asumsi 1 SR melayani & Jiwa & 5 & 5 & 5 & 5 \\
\hline - Jumlah Sambungan Rumah & Unit & 2.633 & 5.174 & 8.344 & 12.143 \\
\hline Asumisi Kebutuhan Air : & & & & & \\
\hline - Sambungan Rumah & $($ //o/h) & 100 & 100 & 100 & 100 \\
\hline Kebutuhan Air Domestik & I/h & 1.316 .490 & 2.587 .150 & 4.172 .210 & 6.071 .670 \\
\hline & I/det & 15,24 & 29,94 & 48,29 & 70,27 \\
\hline Persen Non Domestik & $\%$ & 20 & 20 & 20 & 20 \\
\hline -Total Non Domestik & I/det & 3,05 & 5,99 & 9,66 & 14,05 \\
\hline Total Kebutuhan Air & I/det & 18,28 & 35,93 & 57,95 & 84,33 \\
\hline Kehilangan air & $\%$ & 25 & 25 & 25 & 25 \\
\hline & I/det & 4,57 & 8,98 & 14,49 & 21,08 \\
\hline Kebutuhan Air Rata-Rata & I/det & 22,86 & 44,92 & 72,43 & 105,41 \\
\hline Faktor Hari Maksimum & & 1,10 & 1,10 & 1,10 & 1,10 \\
\hline Kapasitas Produksi & I/det & 25,14 & 49,41 & 79,68 & 115,95 \\
\hline Faktor Jam Puncak & & 1,5 & 1,5 & 1,5 & 1,5 \\
\hline Kapasitas Distribusi & I/det & 34,28 & 67,37 & 108,65 & 158,12 \\
\hline
\end{tabular}




\section{B. Analisa Kondisi Eksisting}

1. Pelayanan Dan Kebutuhan Air (Suply and Demand)

Berdasarkan data PDAM KAbupaten Sambas jumlah pelanggan PDAM masih sangat sedikit yaitu hanya melayani sekitar 12.700 orang pada daerah pelayanan Kecamatan Sambas. Berdasarkan data kecamatan sambas jumlah penduduk Kecamatan Sambas hingga bulan Oktober 2014 tercatat sebanyak 54.050 orang, sehingga jumlah orang yang harus dilayani oleh PDAM sebanyak 42.311 orang yaitu berdasarkan daerah pelayanan PDAM sebanyak 16 desa dari 18 desa yang ada di Kecamatan Sambas. Dengan demikian cakupan pelayanan PDAM pada daerah Kecamatan Sambas hanya melayani 30,01\% dari jumlah penduduk yang harus dilayani.

Beberapa program pengembangan yang harus dilaksanakan oleh pihak PDAM dalam upaya peningkatan pelayanan adalah sebagai berikut:

1. Melakukan optimalisasi intake hingga pipa transmisi agar terus dapat dimanfaatkan hingga tahun 2030.

2. Melakukan peningkatan kapasitas produksi dengan cara rehabilitasi terhadap bangunan IPA dan memanfaatkan instalasi dengan kapasitas 2x10 liter/detik agar dapat dimanfaatkan dan dapat memenuhi kebutuhan air pelanggan hingga tahun 2030.

3. Melakukan pengembangan pemasangan jaringan pipa distribusi di daerah yang belum terpasang jaringan distribusi sehingga dapat menambah sambungan pelanggan.

4. Melakukan pendataan dan pemetaan jaringan pipa dan sambungan rumah aktif maupun tidak aktif.

2. Kehilangan Air

Beberapa faktor yang dapat menyebabkan terjadinya kehilangan air pada jaringan distribusi ini adalah:

1. Umur pipa yang sudah tua yaitu diatas 30 tahun.

2. Tingkat kebocoran yang tidak dapat terdeteksi dengan baik karena tidak terpasangnya alat pengukur debit dan tekanan pada jaringan distribusi.

3. Tidak adanya meter induk sehingga besarnya jumlah air yang didistribusikan tidak dapat diketahui dengan pasti.

4. Sistem perpipaan yang sudah berlumpur dan tidak adanya pengurasan.

5. Pipa distribusi dalam keadaan rusak ringan hingga rusak parah dan tidak adanya perbaikan terhadap jaringan pipa.

6. Accessories perpipaan banyak yang tidak berfungsi, termasuk valve untuk pembagian aliran wilayah pelayanan.

7. Meter air pelanggan banyak yang sudah rusak sehingga pencatatan konsumsi air pelanggan tidak lagi akurat.

Untuk menurunkan angka kehilangan air, perlunya sebuah program ataupun solusi yang dapat mengatasi permasalahan-permasalahan yang menjadi faktor penyebab terjadinya kehilangan air tersebut. Solusi yang dapat dilakukan adalah:

1. Melakukan penggantian meter air pelanggan yang sudah tidak berfungsi dengan baik.

2. Mengganti pipa-pipa distribusi yang telah berusia diatas 30 tahun dengan pipa yang baru agar kebocoran pipa dapat diatasi.

3. Memasang meter induk pada jaringan distribusi agar jumlah air yang didistribusikan dapat diketahui.

4. Melakukan penggantian terhadap accessories pada jaringan distribusi seperti valve agar pembagian debit kewilayah pelayanan dapat dilakukan dengan baik.

5. Pembuatan peta jaringan dan peta pelanggan agar dapat mempermudah dalam melakukan perbaikan terhadap jaringan distribusi. 
3. Peningkatan Tekanan Dan Kontinuitas Aliran Air

Beberapa kendala yang dihadapi oleh PDAM dalam hal peningkatan tekanan dan kontinuitas aliran adalah sebagai berikut:

1. Jam operasi pendistribusian air ke pelanggan hanya selama 18 jam.

2. Daya listrik yang tidak mencukupi untuk melakukan penambahan pompa.

3. Banyaknya kebocoran pipa yang mengakibatkan aliran air tidak merata ke seluruh jaringan pipa.

4. Umur pipa yang sudah tua sehingga permukaan pipa lebih kasar dan mengakibatkan besarnya kehilangan tekanan.

5. Banyaknya endapan lumpur pada pipa sehingga berakibat kepada kehilangan tekanan. Untuk mengatasi permasalahan tersebut diperlukan beberapa solusi dalam upaya peningkatan tekanan dan kontinuitas aliran air hingga tahun perencanaan 2030. Solusi yang dapat dilakukan adalah sebagai berikut:

1. Meningkatkan jam pelayanan selama 24 jam.

2. Melakukan penambahan pompa distribusi agar mencukupi kapasitas distribusi hingga tahun 2030

3. Melakukan penambahan daya listrik agar dapat mencukupi daya pompa yang akan digunakan.

4. Melakukan penambahan kapasitas reservoir sesuai kebutuhan air pada perencanaan tahun 2030. Yaitu 20\% dari kebutuhan air hari maksimum.

5. Mengganti pipa yang telah rusak dengan pipa baru agar dapat mengurangi angka kehilangan tekanan.

6. Melakukan optimaisasi intake dan unit pengolahan.

\section{ANALISA SIMULASI EPANET 2.0 TERHADAP JARINGAN EKSISTING}

Analisa kondisi eksisitng menggunakan software Epanet 2.0 dilakukan dengan dua skenario yaitu skenario pertama menggabarkan kondisi aliran pada jaringan sekarang tanpa adanya modifikasi terhadap jaringan, sedangkan simulasi kedua menggambarkan kondisi aliran pada saat kebutuhan air mengalami peningkatan pada tahun 2020 dengan kondisi jaringan yang tetap sama dengan kondisi jaringan eksisting. Berikut hasil simulasi pertama yang dilakukan pada kondisi jaringan pipa eksisting (Hasil Analisa, 2014):

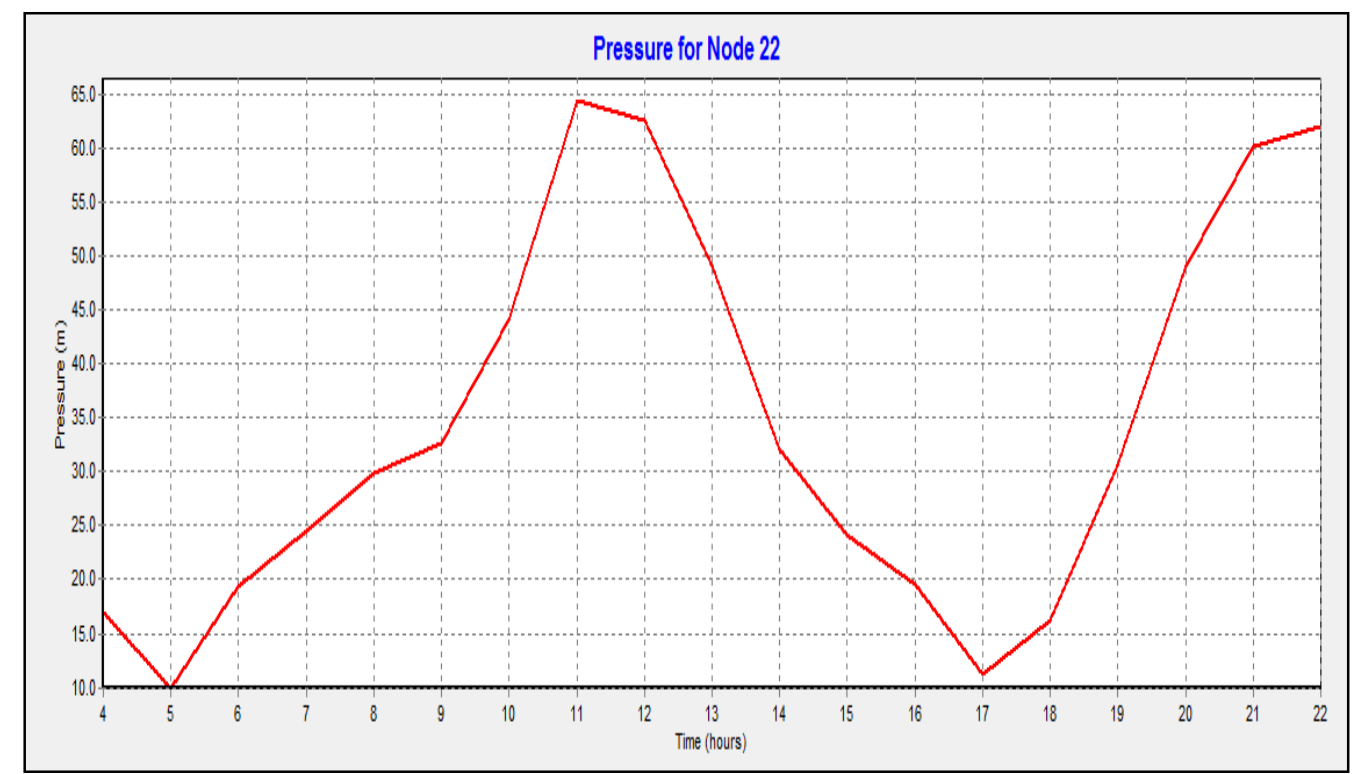

Gambar 1. Grafik Tekanan pada Node 22 (Simulasi 1) 
Grafik tekanan diatas adalah tekanan yang terjadi pada titik 22 yang merupakan titik terjauh dari sumber. Tekanan yang terjadi pada titik tersebut mengalami fluktuasi pada setiap jam yag merupakan akibat dari perubahan pemakaian air oleh konsumen. Tekanan yang diterima pada titik 22 ini merupakan tekanan terkecil jika dibandingkan dengan titiktitik yang lain pada jaringan. Tekanan terkecil terjadi pada jam 05.00 yang merupakan jam puncak pemakaian air pada wilayah Kecamatan Sambas. Pada titik 22 ini tekanan pada jam 05.00 adalah sebesar 9,93 meter, dengan demikian berdasarkan hasil simulasi terhadap jaringan eksisting nilai tekanan di setiap titik masih dapat mendistribusikan air ke semua pelanggan.

Simulasi yang kedua dilakukan dengan cara menambahkan semua kebutuhan pada srtiap titik berdasarkan hasil proyeksi kebutuhan air tahun 2020. Dengan simulasi ini dapat diketahui apakah jaringan eksisting masih mampu mendistribusikan air kesemua pelanggan hingga tahun 2020. Berikut hasil simulasi kedua yang dilakukan pada kondisi jaringan eksisting (Hasil Analisa, 2014):

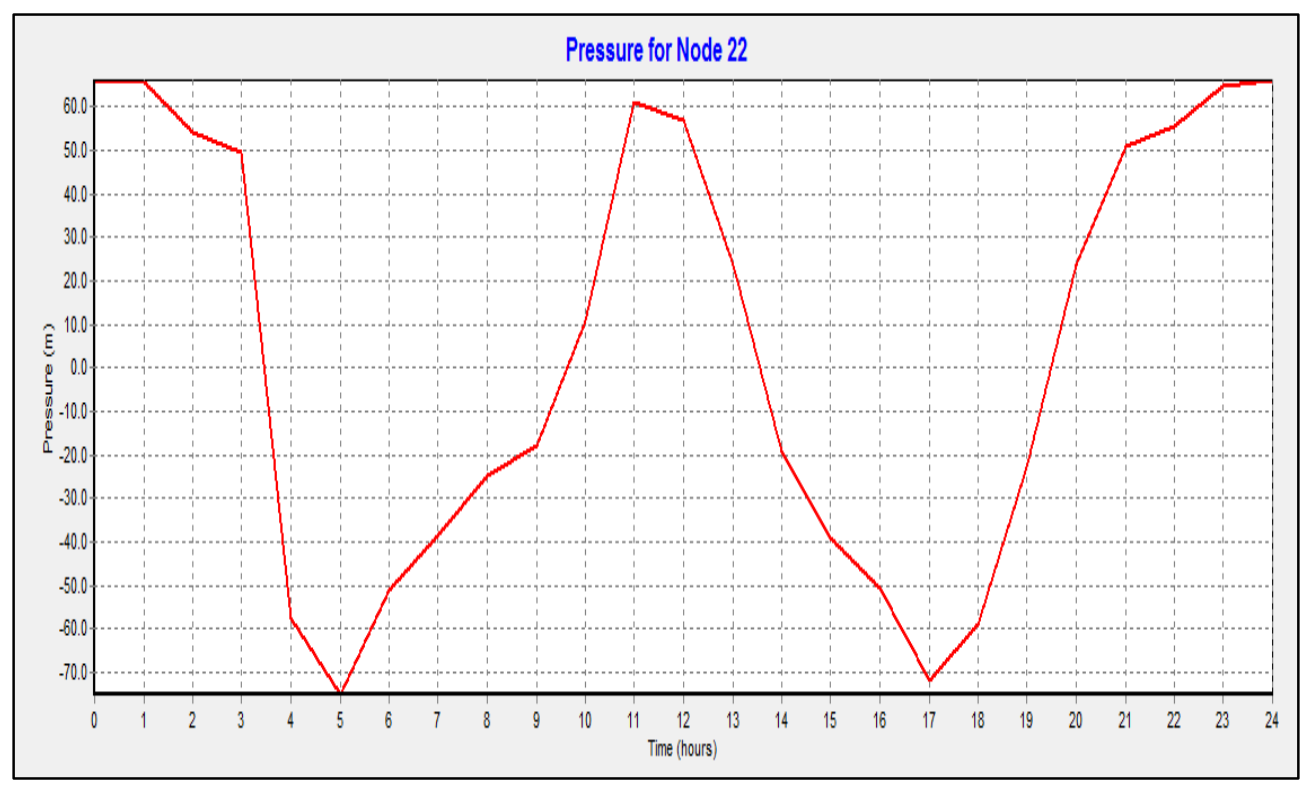

Gambar 2. Grafik Tekanan pada Node 22 (Simulasi 2)

Berdasarkan hasil simulasi diatas dapat dilihat terjadi nilai tekanan yang negatif pada titik 22 ini. Nilai tekanan yang negatif terjadi pada semua titik karena terjadi penambahan kebutuhan air pada setiap titik tersebut. Dengan nilai tekanan yang negatif maka jaringan pipa eksisting tidak mampu mendistribusikan air jika terjadi penambahan kebutuhan oleh pelanggan, maka perlu dilakukan modifikasi terhadap jaringan pipa eksiting dan penambahan kapasitas pompa agar jaringan mampu untuk mendistribusikan air kepada pelanggan.

\section{ANALISA PENGEMBANGAN JARINGAN PIPA DISTRIBUSI}

Pengembangan jaringan distribusi PDAM Pusat Kabupaten Sambas dilakukan berdasarkan hasil simulasi terhadap kondisi eksisting. Perluasan dan pengembangan jaringan akan dilakukan menjadi tiga tahap pengembangan yaitu tahap pertama perencanan tahun 2015-2020, tahap kedua perencanan tahun 2021-2025 dan tahap ketiga perencanaan tahun 2026-2030. Barikut matriks pengembangan jaringan dan pompa yang dilakukan dalam perencanaan ini (Hasil Analisa, 2014): 
Tabel 2. Perencanaan Pengembangan Jaringan Pipa

\begin{tabular}{|c|c|c|c|}
\hline No & Strategi Perencanaan & Lokasi & $\begin{array}{l}\text { Panjang } \\
\text { Pipa (m) }\end{array}$ \\
\hline \multicolumn{4}{|c|}{ Tahun Perencanaan 2015 - 2020} \\
\hline \multirow{5}{*}{1} & \multirow{5}{*}{ Pengembangan Pipa $\varnothing 100$ mm } & - Desa Kartiasa & 1105 \\
\hline & & - Desa Dalam Kaum & 2703 \\
\hline & & - Desa Tumuk Manggis & 950 \\
\hline & & - Desa Saing Rambi & 9940 \\
\hline & & - Desa Lumbang & 300 \\
\hline 2 & Penggantian Pipa $\varnothing 100$ mm & - Desa Tumuk Manggis & 500 \\
\hline \multirow[b]{2}{*}{3} & \multirow{2}{*}{ Pengembangan Pipa $\varnothing 150$ mm } & - Desa Kartiasa & 1834 \\
\hline & & - Desa Lumbang & 1693 \\
\hline 4 & Penggantian Pipa $\varnothing 150$ mm & - Desa Sebayan & 1000 \\
\hline \multicolumn{4}{|c|}{ Tahun Perencanaan 2021 - 2025} \\
\hline \multirow[b]{2}{*}{1} & \multirow{2}{*}{ Penggantian Pipa $\varnothing 150$ mm } & - Desa Lubuk Dagang & 1000 \\
\hline & & - Desa Lumbang & 1331 \\
\hline \multirow{2}{*}{2} & \multirow{2}{*}{ Penggantian Pipa $\varnothing 200$ mm } & - Desa Durian & 1000 \\
\hline & & - Desa Lorong & 1542 \\
\hline \multirow{2}{*}{3} & \multirow{2}{*}{ Pengembangan Pipa $\varnothing 100$ mm } & - Desa Kartiasa & 1000 \\
\hline & & - Desa Dalam Kaum & 1200 \\
\hline \multirow{2}{*}{4} & \multirow{2}{*}{ Pengembangan Pipa $\varnothing 150$ mm } & - Desa Sebayan & 1518 \\
\hline & & - Desa Lumbang & 800 \\
\hline 5 & Penggantian Pipa $\varnothing 250$ mm & - Desa Durian & 550 \\
\hline \multicolumn{4}{|c|}{ Tahun Perencanaan 2026 - 2030} \\
\hline \multirow{3}{*}{1} & \multirow{3}{*}{ Penggantian Pipa $\varnothing 150$ mm } & - Desa Saing Rambi & 1775 \\
\hline & & - Desa Dalam Kaum & 2926 \\
\hline & & - Desa Tanjung Mekar & 497 \\
\hline \multirow{4}{*}{2} & \multirow{4}{*}{ Penggantian Pipa $\varnothing 200$ mm } & - Desa Kartiasa & 1834 \\
\hline & & - Desa Durian & 868 \\
\hline & & - Desa Pasar Melayu & 877 \\
\hline & & - Desa Jagur & 1196 \\
\hline
\end{tabular}

Tabel 3. Perencaan Pengembangan Pompa

\begin{tabular}{|l|l|l|l|l|}
\hline No & $\begin{array}{c}\text { Kapasitas Pompa } \\
\text { yang digunakan }\end{array}$ & Pemasangan & Jadwal Operasi & Keterangan \\
\hline \multicolumn{5}{|c|}{ Tahun Perencanaan 2015 - 2020 } \\
\hline 1 & $30 \mathrm{I} /$ det Head $=50 \mathrm{~m}$ & Eksisting & $18 \mathrm{Jam}(04.00-22.00)$ & Optimalisasi \\
\hline 2 & $30 \mathrm{I} /$ det Head $=50 \mathrm{~m}$ & 2020 & $24 \mathrm{Jam}$ & Penambahan \\
\hline \multicolumn{7}{|c|}{ Tahun Perencanaan 2021 - 2025 } \\
\hline 1 & $30 \mathrm{l} /$ det Head $=50 \mathrm{~m}$ & 2020 & $24 \mathrm{Jam}$ & Optimalisasi \\
\hline
\end{tabular}




\begin{tabular}{|l|l|l|l|l|}
\hline No & $\begin{array}{c}\text { Kapasitas Pompa } \\
\text { yang digunakan }\end{array}$ & Pemasangan & Jadwal Operasi & Keterangan \\
\hline 2 & $80 \mathrm{l} /$ det Head $=40 \mathrm{~m}$ & 2025 & 18 Jam (04.00-22.00) & Penambahan \\
\hline \multicolumn{5}{|c|}{ Tahun Perencanaan $2026-2030$} \\
\hline 1 & $30 \mathrm{l} /$ det Head $=50 \mathrm{~m}$ & 2015 & $7 \mathrm{Jam}(22.00-03.00)$ & Optimalisasi \\
\hline 2 & $80 \mathrm{l} /$ det Head $=40 \mathrm{~m}$ & 2025 & 17 Jam (04.00-21.00) & Optimalisasi \\
\hline 3 & $80 \mathrm{l} /$ det Head $=40 \mathrm{~m}$ & 2030 & 19 Jam (03.00-22.00) & Penambahan \\
\hline
\end{tabular}

\section{E. Analisa Perencanaan Pada Simulasi Epanet}

Berdasarkan hasil simulai yang dilakukan terjadi fluktuasi tekanan pada setiap jam untuk semua node. Nilai tekanan terkecil terjadi pada jam 05.00 karena besarnya pemakaian air pada jam tersebut sedangkan nilai tekanan terbesar terjadi pada jam 00.00 karena pemakaian yang sangat kecil. Besarnya nilai pemakaian pada simulasi ini marupakan akibat dari nilai pattern yang telah di input kedalam program epanet. Berikut grafik tekanan yang yang terjadi pada hasil simulasi pada software Epanet 2.0 (Hasil Analisa, 2014):

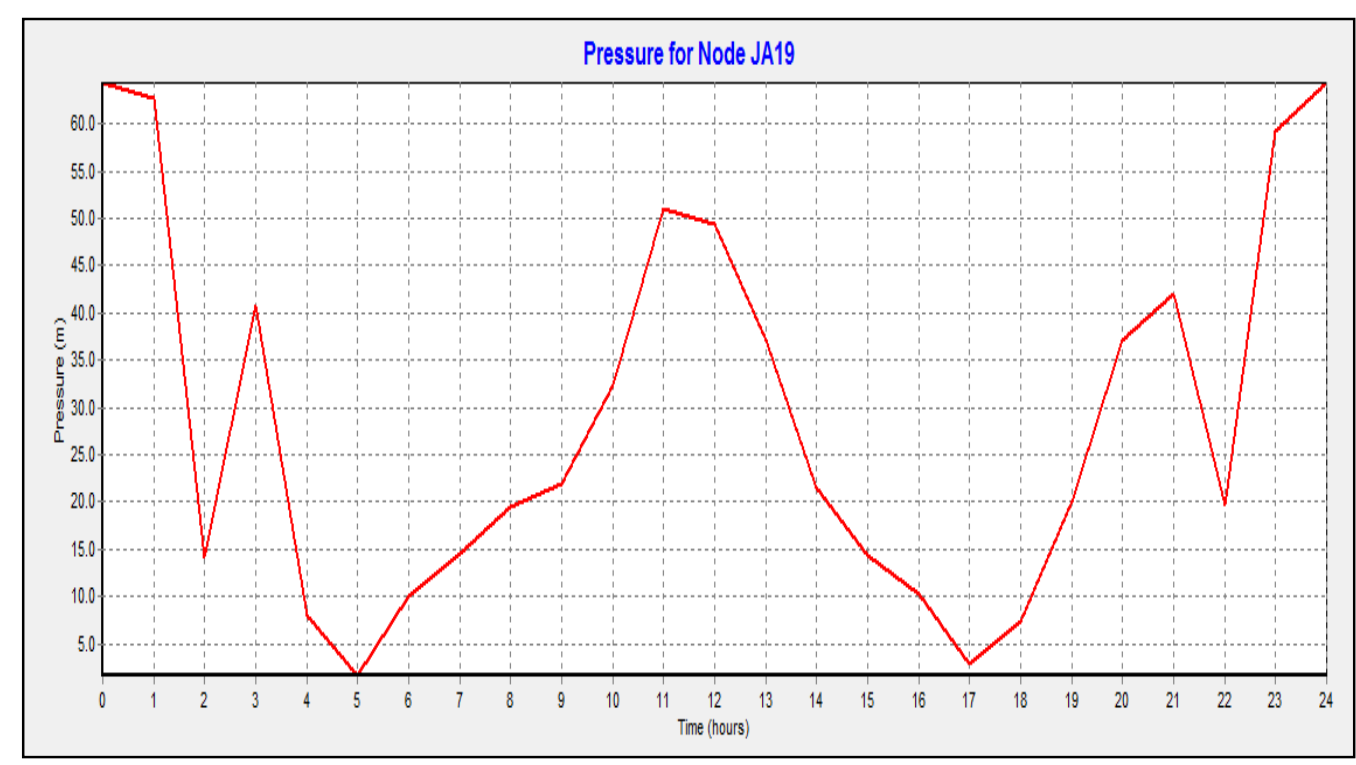

Gambar 3. Grafik Tekanan Pada Node JA19

Berdasarkan Gambar 3 diatas yang merupakan grafik tekanan yang terjadi pada Node JA19 terjadi fluktuasi tekanan dalam setiap jam. Fluktuasi tekanan ini terjadi karena pengaruh dari jumlah pemakaian air oleh konsumen yang tidak menentu pada setiap jam nya. Besarnya pemakaian air oleh konsumen ini sangat mempengaruhi nilai kehilangan tekanan yang terjadi pada setiap pipa. Dalam analisa hidrolis ini sebuah aliran fluida mengalir dalam satu luasan penampang yang tetap dan panjang penampang yang tetap, sehingga yang mempengaruhi nilai perubahan kehilangan tekanan adalah besarnya debit yang mengalir pada pipa tersebut. Besarnya debit yang mengalir pada pipa merupakan jumlah pemakaian air oleh pelanggan.

Perubahan tekanan pada jaringan distribusi juga merupakan pengaruh dari penggantian pompa dari kapasitas kecil ke kapasitas besar sehingga tekanan yang dikeluarkan pompa akan besar pula. Besarnya tekanan yang dikeluarkan pompa akan menaikkan tekanan pada Node saat dijalankan simulasi. Setiap Node pada jaringan menunjukkan pola grafik tekanan yang sama karena pengaruh fluktuasi tekanan juga sama pada setiap Nodenya. 
Penjadwalan terhadap pompa dilakukan agar dapat menghemat biaya yang dikeluarkan untuk operasional pompa.

Tekanan pada Node JA19 merupakan tekanan terkecil pada semua Node dalam satu jaringan. Tekanan terkecil terjadi pada jam puncak pemakaian air oleh konsumen, yaitu terjadi pada jam 05.00 dengan tekanan sebesar 1,63 meter pada Node JA19 yang merupakan daerah pelayanan Desa Saing Rambi. Tekanan pada Node JA19 akan terus naik dari jam 06.00 hingga jam 11.00 yaitu sebesar 10,11 meter pada jam 06.00 dan 51,12 meter pada jam 11.00.

Besarnya nilai kebutuhan oleh pelanggan dapat dilihat dari grafik kehilangan air pada reservoir yang akan ditampilkan pada gambar 4 dibawah ini (Hasil Analisa, 2014):

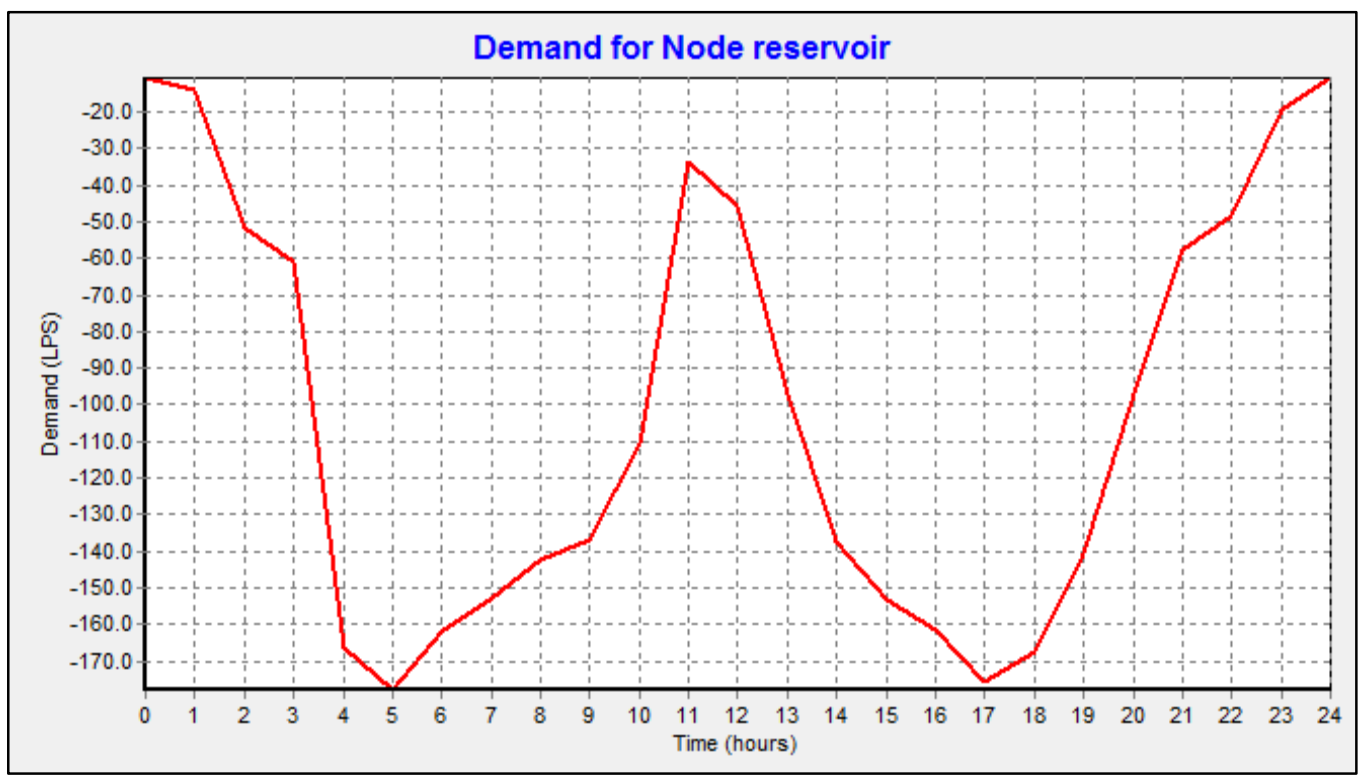

Gambar 4. Grafik Demand Pada Reservoir

Besarnya pemakaian oleh konsumen dapat dilihat dari Gambar 4 diatas. Nilai kebutuhan akan terus mengalami peningkatan hingga jam puncak pemakaian yaitu jam 05.00 dan mengalami penurunan pemakaian hingga jam 11.00. Pola grafik ini berbanding terbalik dengan grafik tekanan pada Node, karena nilai tekanan semakin kecil dipengaruhi oleh nilai pemakaian yang semakin besar oleh konsumen.

Berdasarkan hasil simulasi terhadap jaringan yang telah direncanakan, maka jaringan ini dianggap telah memenuhi syarat dan mampu untuk mendistribusikan air kepada konsumen secar continue dan dapat memenuhi sebanyak $90 \%$ kebutuhan air masyarakat Kecamatan Sambas.

\section{KESIMPULAN}

Dari hasil perencanan didapatlah kesimpulan sebagai berikut:

- Kondisi eksisting jaringan distribusi PDAM Pusat Kabupaten Sambas masih banyak mengalami permasalahan. Permasalahan yang dihadapi adalah kurangnya jaringan pipa dalam memenuhi kebutuhan pada daerah pelayanan, banyaknya kebocoran pada jaringan yang tidak dapat terdeteksi, dan kontinuitas aliran yang tidak terpenuhi secara continue.

- Dalam upaya pengembangan jaringan distribusi maka perlu dilakukan perbaikan terhadap jaringan yaitu menambah perluasan jaringan pipa, penambahan kapasitas pompa, penambahan dimensi pipa dan penggantian pipa yang sudah berumur diatas 30 tahun.

- Kapasitas jaringan direncanakan dapat memenuhi 90\% kebutuhan air masyarakat pada daerah pelayanan dengan kebutuhan air sebesar $158 \mathrm{l} /$ det pada jam puncak pemakaian. 


\section{UCAPAN TERIMAKASIH}

Puji dan syukur kehadirat Allah SWT, karena atas berkat rahmat dan Hidayah-Nya maka penulisan Jurnal dengan judul "Evaluasi dan Perencanaan Pengembangan Jaringan Distribusi PDAM Pusat Kabupaten Sambas" ini dapat diselesaikan. Secara khusus penulis menyampaikan terima kasih yang sebesar-besarnya kepada Kedua Orang Tua yang selalu memberi semangat dan motifasi yang kuat dalam penulisan ini serta kepada Bapak Winardi, ST, MT. dan Bapak Eko Yulianto, ST, MT. sebagai pembimbing utama dan pembimbing pendamping yang telah memberikan bimbingan, masukan, diskusi intensif khususnya mengenai sistem distribusi air bersih yang digunakan. Terima kasih disampaikan pula kepada PDAM Kabupaten Sambas serta seluruh pihak yang telah membantu serta memberikan dukungannya selama ini.

\section{Referensi}

Departemen Pekerjaan Umum, Direktorat Jendral Cipta Karya. 2000. Petunjuk Teknis Pengelolaan Sistem Penyediaan Air Minum Perkotaan. Jakarta: Dept. Pu

Ray K. Linsley \& Joseph B. Franzini, 1996. Teknik Sumber Daya Air. Jilid 2. Edisi Ketiga. Jakarta: Erlangga. Rossman, Lewis. A, 2000, Epanet 2 User Manual, Water Supply and Water Resources Division. National Risk Management Research Laboratory, Cincinnati, $\mathrm{OH}$.

Sularso, Haruto Tahara. 2000. Pompa dan Kompressor: Pemilihan, Pemakaian dan Pemeliharaan. Jakarta: PT. Pradnya Paramitha. 